\title{
Alienación, comunicación y consumo: Retos del socialismo del siglo XXI"
}

\author{
ELÍAS CAPRILES
}

Universidad de Los Andes, Mérida

RESUMEN: El concepto marxista de alienación se aproxima a este fenómeno desde su vinculación con las relaciones económicas de producción. En este artículo, el autor parte de ese concepto para explorar sus implicaciones comunicativas y ecológicas. Un socialismo que no caiga en el reduccionismo económico debe considerar estos factores para ser una verdadera alternativa a la alienación capitalista.

ABSTRACT: Marxist concept of alienation is pretty linked with the economic production rela-
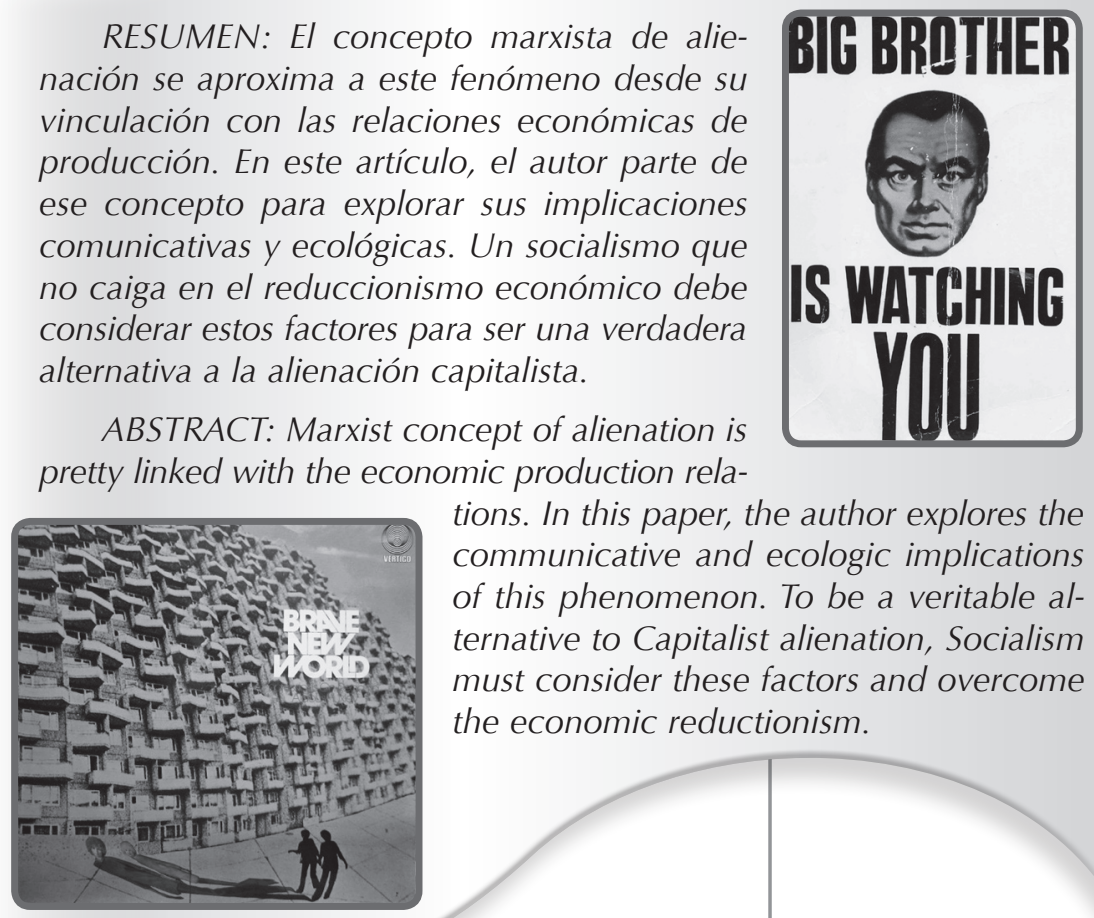

tions. In this paper, the author explores the communicative and ecologic implications of this phenomenon. To be a veritable alternative to Capitalist alienation, Socialism must consider these factors and overcome the economic reductionism.

* Ponencia presentada en el IV Foro Internacional de Filosofía, "Alienación, comunicación y consumo: Retos para el socialismo del siglo XXI", Venezuela, julio de 2008. 


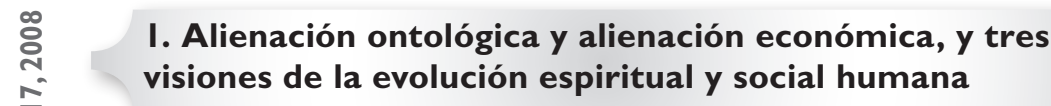

M arx se ocupó de la alienación principalmente en el sentido cultural (alienación del ser humano en la cultura) y, como Feuerbach, en el natural-social —en este último plano, enfatizando la alienación del individuo humano en el trabajo-. Esta última implicaba la separación entre el productor y la propiedad de sus condiciones de trabajo, con lo cual los medios de producción se transformaban en capital (en la medida en que individuos distintos de los productores se habían apropiado de ellos) y al mismo tiempo los productores se transformaban en asalariados (con lo cual el "capital" se apropiaba de una porción leonina de los frutos del trabajo): éste era el concepto de alienación que nos daba Das Kapital, I, iii (Marx, 1959). En este sentido la alienación es el hacerse alieno, o, para expresarlo en castellano, el hacerse ajeno -O sea, la enajenación - con respecto al trabajador, no sólo de los frutos de su propio trabajo, sino también de los medios de producción. Para Marx, la alienación así concebida Ilegaría a su fin cuando el productor se (re-)apropiara el trabajo y los frutos del mismo que habían dejado de pertenecerle (el "plus" del trabajo), terminando con la esclavitud que seguía de esta falta de pertenencia y dando inicio a la libertad -que así quedaba reducida a la apropiación-. A primera vista, esta visión de la desalienación y la libertad parece convertirlas en categorías económicas ${ }^{1}$.

Para Engels, el ser humano se alienó de sí mismo en el curso de la historia, pero se desalienará en el futuro: para el principal colaborador de Marx, la dimensión esencial de la alienación era la económica, la cual no podría haber existido en el comunismo primitivo, en el cual nadie se apropiaba del trabajo y los frutos del trabajo de nadie, como tampoco podrá existir en el comunismo que representará el final de la historia, en el que tampoco podrá existir este tipo de apropiación. En cambio, por lo general se piensa que para Marx el ser humano estuvo siempre alienado y la alienación sólo dejará de existir en el futuro -lo cual por los motivos que se acaban de exponer no sería posible si Marx no hubiese tomado en cuenta dimensiones distintas de la económica. Aunque, como verá más adelante, desde la perspectiva de este trabajo la tesis de que la humanidad siempre estuvo alienada es a todas luces errónea-. Que la alienación tenía para Marx dimensiones no económicas estaba ya claro en los Manuscritos económicos y filosóficos de 1844, donde el revolucionario alemán explicó el comunismo futuro como la superación positiva de la alienación y el retorno del individuo humano a 
su existencia propiamente humana - véase social - a partir de la condición alienada representada por la religión, la familia, el Estado y así sucesivamente -lo cual, como se verá luego, en el plano religioso implicaría la "transustanciación de dios en el comunismo" - . Puesto que esto deja en claro que ni la visión marxiana de la alienación se puede reducir a la explicación dada en el párrafo anterior, ni la visión marxiana de la desalienación se puede reducir a la mera superación de la separación entre el productor y la propiedad de sus condiciones de trabajo que haría que los medios de producción dejasen de ser capital y los productores dejasen de ser asalariados, está claro que para Marx alienación y desalienación eran mucho más que categorías económicas.

Marx y Engels, además de vivir en una época en la que todavía era posible creer en el progreso, fueron directamente influenciados por ese apóstol de la visión de la evolución espiritual y social de la humanidad como perfeccionamiento progresivo que fue Hegel. En consecuencia, concibieron dicha evolución como progreso y perfeccionamiento constantes. Puesto que en su época todavía no era evidente la crisis ecológica, pudieron desarrollar una visión economicista de ese supuesto progreso y perfeccionamiento, según la cual todos los sistemas económicos surgidos en el curso de la historia adolecieron de una deficiencia y el único sistema perfecto sería el último que habría de tener la humanidad: el comunismo que habría de suceder al socialismo. En efecto, desde su óptica el comunismo primitivo estaba signado por la escasez y la penuria, y en esa medida era imperfecto. Una vez que llegó a producir mayor riqueza de la que podía manejar, hubo que sustituirlo por otro capaz de manejarla, así como de producir mayor riqueza que el sistema anterior -aunque ello al mismo tiempo daría lugar a la desigualdad. Cada uno de los sistemas siguientes surgiría para manejar volúmenes de riqueza que el anterior había sido incapaz de manejar, y tendría que ser remplazado por otro cuando ya no fuese capaz de manejar los niveles de riqueza que había producido. Marx y Engels llegaron a la conclusión que las sucesivas crisis que el capitalismo sufrió en su época mostraban que ya no era capaz de manejar los recursos que había creado, y que, por lo tanto, había llegado la hora de sustituirlo por el socialismo, que crearía recursos todavía mayores al tiempo que redistribuiría la riqueza de una manera más igualitaria, usando el Estado de manera contraria a los sistemas anteriores, pues en vez de hacerlo para servir a los intereses de la clase económicamente dominante, lo emplearía para poner coto al dominio económico de ésta y al mismo tiempo poner fin a la alienación económica, haciendo posible que el trabajador recibiera los frutos de su trabajo sin que un capitalista se apropiase la mayor. A su vez, el socialismo, una vez que 
llegase a producir volúmenes de riqueza que no fuese ya capaz de manejar, debería ser remplazado por el comunismo, en el cual la sobreabundancia de bienes haría posible que todos aportasen su trabajo según sus posibilidades y recibiesen, no ya proporcionalmente a su aporte (como habría sido el caso en el socialismo), sino según sus necesidades, y en el cual el Estado no sería ya necesario ni para defender los intereses de una clase dominante ni para poner coto a los privilegios de la misma, por lo cual desaparecería junto con la propiedad privada y la familia ${ }^{2}$.

En nuestros días, los volúmenes de producción del capitalismo han creado una crisis ecológica que, según los científicos más objetivos, amenaza con desintegrar las sociedades humanas y muy probablemente poner fin a nuestra especie en el plazo del presente siglo ${ }^{3}$. Esto ha refutado el economicismo inherente al marxismo, pues si los países con menores volúmenes de producción y consumo tuviesen que incrementar considerablemente dichos volúmenes antes de que la transición al socialismo se hiciese posible, y si en los países con los mayores niveles de producción y consumo un estadio de socialismo tuviese que hacer aumentar dichos niveles más allá de su nivel actual para que luego el comunismo se hiciese posible, la especie humana se extinguiría mucho antes de que en los países de menor "desarrollo" económico el socialismo pudiese implementarse, y de que en los países de mayor "desarrollo" económico el comunismo pudiera establecerse.

De hecho, la actual crisis ecológica y social ha demostrado que en lo espiritual y en lo social la humanidad no ha estado progresando, sino degenerando. Esta degeneración ha sido el resultado del desarrollo progresivo de la alienación. No sólo en el sentido económico privilegiado por Marx y Engels, sino, más esencialmente aún, en el ontológico, del cual la alienación económica no es más que un aspecto y un desarrollo. Puesto que los padres del marxismo jamás hicieron referencia a una alienación ontológica, el lector podría pensar que aquí se está haciendo referencia a la visión de Hegel, para quien la alienación o enajenación -que él designó por los términos Entäusserung, Entzweiung, Trennung y Entfremdung - era de un tipo que muy bien podríamos caracterizar como ontológico, pues ella no era otra cosa que la manifestación del espíritu (Geist) o la idea como naturaleza o realidad física (o sea, como no-espíritu o como no-idea) -lo cual implicaba la existencia de una esencia que el espíritu / idea, y por implicación el individuo humano dejaba de encarnar, haciéndose ajeno a ella-. En efecto, para el idealismo absoluto, la naturaleza y el mundo material eran proyecciones del espíritu o la idea que sin embargo se definían por contraste con éstos, y en consecuencia la aparición 
de aquéllos hacía a algo que era espíritu/idea ajeno al espíritu/idea - lo que para Hegel significaba que el espíritu/idea, al igual que el individuo humano individual, se hacían ajenos a sí mismos-. Para Hegel, el extremo de la alienación se daba al comienzo de la evolución espiritual y social humana, en la certeza sensible que para la Fenomenología del espíritu (Hegel, 1966) era el estadio inicial de desarrollo del espíritu, y que consistía en tener la certeza de que lo percibido era algo ajeno a uno mismo que existía por sí mismo en un mundo externo igualmente autoexistente - cuando, como se acaba de ver, en verdad no lo eraPuesto que el agente de la proyección del espíritu o la idea como la naturaleza o el mundo físico no era otro que el espíritu/idea, y puesto que quien en la certeza sensible - primer nivel de desarrollo del espíritu en la Fenomenología- ponía y al mismo tiempo experimentaba el mundo físico/la naturaleza como algo externo y ajeno a sí mismo era el individuo humano, la alienación era autoalienación. Para Hegel, la alienación hacía de la conciencia humana una conciencia desdichada. Ahora bien, ni la alienación ni la conciencia desdichada podrían continuar por siempre: la evolución espiritual y social de nuestra especie constituía un proceso de desalienación en el cual cada estadio representaba un incremento de verdad y plenitud con respecto al estadio anterior, y que finalmente daría lugar a la verdad y la plenitud totales o absolutas con el autorreconocimiento de la idea o el espíritu, ahora como autoconciencia, en la naturaleza - lo cual implicaría alcanzar una reconciliación (Versöhnung) de la conciencia con lo que había llegado a experimentar como ajeno a sí misma, la cual constituiría al mismo tiempo una reunión (Vereignigung) y una apropiación (Aneignung) en la medida en que en dicha reconciliación se conservaría la autoconciencia que se habría desarrollado en el proceso de desarrollo de la alienación.

Desde la óptica de este trabajo, por el contrario, la alienación ontológica -que es una función del error o la delusión que el Buda llamó avidya y que Heráclito designó como lethe ${ }^{4}$, y que en otros trabajos (Capriles, 1994, 2007a vol. I, etc.) he explicado en términos de una modificación de la interpretación sartreana de los conceptos de Símismo (Soi) y ser-para-Sí (être-poursoi) - consiste en sentirnos separados del continuo de energía que para la física actual es el universo y que es lo que somos en verdad en la medida en que nuestro cuerpo, nuestra energía vital, y nuestro pensamiento y en general todo lo que consideramos como mental son todos ellos aspectos o segmentos indivisibles de dicho continuo, fuera del cual simplemente no hay nada. Desde esta perspectiva, originalmente los seres humanos nos habríamos encontrado libres de la alienación que se acaba de explicar, y en general de todo tipo de alienación, pues no nos habríamos 
experimentado como ajenos al continuo de energía de la physis que somos en verdad. Habría sido en el momento mismo cuando surge la sensación de hallarnos intrínsecamente separados del todo, del cual somos segmentos indivisibles, que habría surgido la alienación, la cual se habría ido desarrollando a medida que se habría ido incrementando dicha sensación, con lo cual la conciencia humana se habría ido haciendo cada vez más desdichada: con la aparición de la dualidad sujeto-objeto y de la concomitante ilusión de separatividad que sufre la conciencia asociada al sujeto mental, la totalidad se fractura en nuestra experiencia, a raíz de lo cual surge una vivencia de carencia de totalidad, mientras que la ilusoria separación de nuestra conciencia con respecto al continuo ininterrumpido y totalmente pleno (en la medida en que está libre de espacios vacíos) que para Einstein es el universo da lugar a una experiencia de carencia de la plenitud inherente a dicho continuo - una sensación de carencia que se desarrolla a medida que nuestra ilusión de separatividad se hace más pronunciadaDel mismo modo, puesto que el sujeto que se cree separado de los objetos acepta unos y rechaza otros según el carácter que percibe en ellos, entrando así en conflicto con los últimos, queda condenado al conflicto. Por consiguiente, en tanto que la conciencia humana siga experimentándose como separada del continuo de la physis y de los objetos que la percepción humana abstrae en dicho continuo, no habrá manera de que deje de ser conciencia desdichada: contrariamente a la visión de Hegel, ella estará sujeta al fatalismo sartreano (Sartre, 1980), que consiste en no tener posibilidad alguna de superación de su estado de desdicha. Más aún, la sensación de carencia de plenitud nos hará consumir desenfrenadamente en un intento infructuoso por tratar de colmar dicha carencia, mientras que el conflicto con los aspectos de la physis que percibimos como algo amenazador hará que intentamos destruirlos $-\mathrm{y}$ en consecuencia la alienación ontológica que corresponde a la avidya/lethe es la raíz más profunda de la crisis ecológica-. Por lo tanto, desde nuestra perspectiva, la única desalienación genuina posible es la que tiene lugar cuando desaparece la autoconciencia junto con el sujeto mental que erróneamente se experimenta como separado del continuo de la physis, y así tiene lugar el des-cubrimiento de la verdadera condición de nosotros mismos y de todo el universo, más allá de la dualidad sujeto-objeto y de todos los conceptos. El motivo por el que este descubri-miento sólo puede ocurrir más allá de los conceptos y de la dualidad sujeto-objeto $-y$, por lo tanto de la autoconciencia, que tiene la dualidad sujeto-objeto como su condición de posibilidad - es que la verdadera condición de nosotros mismos y de todo el universo es aquello que nada excluye, mientras que los conceptos en general y el sujeto y el objeto en particular por 
su propia naturaleza siempre excluyen algo: los conceptos se definen por género próximo y diferencia específica (y tener diferencia específica implica contrastar con algo que en consecuencia queda excluido), mientras que el sujeto y el objeto se excluyen mutuamente.

Desde esta perspectiva, pues, lo que Hegel pretendía, incluso en el supuesto negado de que la naturaleza fuese la proyección aparentemente externa de la idea, tendría que dar lugar a un error mayor que el constituido por tomar como ajeno algo que no lo es, pues la conservación de la autoconciencia implicaría la conservación de la ilusoria separación del sujeto mental con respecto al continuo de la physis que constituye su verdadera condición; $y$, sin embargo, este sujeto mental autoconsciente ahora se ocultaría a sí mismo su aparente separación con respecto al continuo de energía que para la física actual es el universo al percibir conceptualmente la naturaleza y en general todo lo material como una proyección de sí mismo: como he explicado en gran detalle en el artículo "La inversión hegeliana de la historia" (Capriles, 1992) y en los libros Individuo, sociedad, ecosistema (Capriles, 1994) y Beyond History (Capriles, 2007a vol. III), esta operación constituiría un autoengaño del tipo que JeanPaul Sartre (1980) designó como mala $\mathrm{fe}^{5}$, y que Ronald D. Laing (1961) designó como elusión y representó en términos de una espiral de simulaciones; $y$, por lo tanto, al contrario de lo que creyó Hegel, implicaría menos verdad y completud (o, lo que es lo mismo, mayor falsedad y fragmentación).

Está claro, pues, que la primera forma de alienación en surgir, según nuestra visión, es la ontológica - que, como vimos, es una función del error o la delusión que el Buda Ilamó avidya y que Heráclito designó como lethe, y que, como se verá a continuación, implica la aparición de un ser-para-Sí aproximadamente como lo entendió Sartre, que se experimenta como encontrándose a una distancia de su verdadera condición, que es absoluta plenitud y que corresponde a mi reinterpretación de lo que Sartre Ilamó Sí-mismo - y que todas las demás formas de alienación no son más que aspectos y desarrollos de esta alienación esencial. El mito judeocristiano-musulmán expuesto en el Libro del Génesis, que simboliza la Caída de la raza humana con el relato según el cual Adán y Eva comieron el fruto del Árbol del Conocimiento del bien y el mal, ilustra la aparición de dicha alienación, que, en su forma más palpable, ocurre con la aparición de la dualidad sujeto-objeto, que es la condición de posibilidad del juicio, y la inmediata aparición de este último. En alemán, éste se designa como Urteil, que etimológicamente significa partición originaria: la primera partición es la que introdujo la aparición de la dualidad sujeto-objeto, que hizo que los seres humanos se sintieran claramente separados del 
resto del universo -incluyendo a los otros seres humanos-, y de inmediato el juicio mismo opuso el bien al mal, lo bello a lo feo, el placer al dolor, el amor al odio y así sucesivamente, en una serie ilimitada de dualidades.

La condición anterior a la partición originaria, que habría sido la condición original de nuestra especie, habría sido aquella que en distintas obras he designado por el término sacramental cristiano "Comunión", que decidí llamar de esta manera porque en ella los seres humanos vivenciábamos juntos la verdadera naturaleza común a todos nosotros y a la totalidad del universo. La alienación ontológica habría interrumpido esta Comunión: el Símismo o Soi de Sartre, como yo lo he redefinido, es nuestra verdadera condición indivisa, que a diferencia del filósofo francés he ilustrado con el continuo de energía que según Einstein es el universo (en Capriles, 2007a, vol. I, se revelan las contradicciones inherentes a la definición que Sartre [1980] da del término; sin embargo, también se muestra que las explicaciones subsiguientes que con respecto al Sí-mismo da dicho autor en la mencionada obra implican que comprende tanto lo que normalmente consideramos como el mundo material como la capacidad Gnitiva —o Gnitividadhumana ${ }^{6}$ ), el cual se hace patente en el estado que Ilamo de "Comunión", mientras que el ser-para-Sí es la ilusoria alienación, enajenación o separación de la conciencia dualista asociada al sujeto mental con respecto a dicha verdadera condición indivisa, la cual implica sentirnos intrínsecamente separados del medio ambiente que incluye al resto de los seres humanos y otros seres vivos. Es así que, por las razones antes explicadas, aparece la conciencia desdichada.

Es el desarrollo de la alienación ontológica $-\mathrm{y}$ por lo tanto de la avidya o lethe, de la alienación del ser-para-Sí con respecto al Sí-mismo y de la fuerza del juicio- más allá de un nivel umbral, lo que hace que de allí en adelante unos seres humanos se propongan someter a otros tantos en lo político como en lo económico y lo social, y que más tarde concibamos lo que Gregory Bateson (1968 y 1972) Ilamó "propósito consciente contra la naturaleza". Es por esto que con anterioridad se señaló que la alienación económica no era más que un aspecto y un desarrollo de la alienación ontológica. Cabe señalar que se puede dividir el desarrollo en cuestión en los estadios relacionales que se van sucediendo después del final del estadio de Comunión en el que todavía no se había desarrollado la alienación ontológica —o sea, en el cual todavía no había aparecido en ser-para-Sí, pues no se había desarrollado el error o la delusión que el Buda Ilamó avidya y que Heráclito designó como lethe-, que era no-relacional en la medida en que todavía no se había producido la ilusión de multiplicidad que es la condición de posibilidad de las 
relaciones entre distintos entes. En efecto, en dicho estadio imperaba lo que la enseñanza dzogchén Ilama vidya y que en mi interpretación sería lo que Heráclito Ilamó aletheia o "no-ocultación" (una interpretación de dicha aletheia que contradice la que propuso Heidegger [1971] en el $\S 44 \mathrm{~B}$ de Ser y tiempo y la que más adelante dio el mismo autor en Aletheia [1943], y en general buena parte de las producidas hasta ahora: cfr. Capriles, 2007a, vol. I).

Por supuesto, dicho estadio, que en las tradiciones que consideran nuestra evolución espiritual y social como un proceso de degeneración corresponde al comienzo mismo de la Edad de Oro, Era de Perfección (krityayuga) o Era de la Verdad (satyayuga), es en gran parte hipotético. En la práctica, la primera de las eras o edades habría estado caracterizada por la alternación entre el estado no relacional de no-alienación, vidya y aletheia que aquí designo por el término sacramental cristiano "Comunión", y un estado relacional que he Ilamado de "post-Comunión" que, en la medida en "relación" implica la existencia de entes separados que se relacionan entre sí, tendría como eje el error llamado avidya o lethe y por lo tanto la alienación ontológica. Sin embargo, puesto que en este estadio todavía no hay un foco de conciencia tan hermético como para poder ignorar totalmente la pasión y el dolor del otro, hay compasión en el sentido de apertura a la pasión del otro, y, por lo tanto, todas las relaciones serían comunicativas en el sentido de tratar al otro-sea éste humano, animal, vegetal o mineral-como un sujeto a respetar.

Una vez que la mayoría de los seres humanos pierde la capacidad de acceder al estado de Comunión, pero antes de que el error que constituye la alienación ontológica se haya desarrollado al grado de hacernos percibir y tratar a los demás entes, sensibles o no, como objetos a manipular, y en tanto que todavía se conserve la memoria del estado en el cual se hacía patente que tanto los seres que sienten como los entes insensibles eran todos aspectos o segmentos del continuo de la physis que constituye nuestra verdadera condición y naturaleza $-y$ no útiles intrínsecamente separados de nosotros a explotar, dominar y manipular - todavía se mantiene una condición similar a la del estado de post-Comunión. Es por ello que a este segundo estadio podemos llamarlo "estadio comunicativo" -término en el cual "comunicativo" tiene el sentido de percibir y tratar a todo aquello con lo que nos relacionamos como un sujeto que merece respeto y no como un útil a manipular.

Finalmente, el último de los estadios en cuestión sería el instrumental, en el cual el error que corresponde a la alienación ontológica se ha desarrollado a tal grado y el foco de conciencia se ha hecho tan hermético que por una parte ya no hay ninguna conciencia de las interrelaciones ecológicas, y por la otra 
se puede ignorar el padecimiento ajeno - lo cual permite que intentemos dominar, oprimir y explotar a los demás seres humanos, al resto de los animales, y en general a la totalidad de la ecosfera. En efecto, aquí "instrumental" tiene el sentido de tratar a todo aquello con lo que nos relacionamos como útiles insensibles que se emplean para lograr nuestros propios fines egoístas.

Antes de la aparición de dioses supramundanos y de la práctica de la agricultura, la estructura de la psiquis humana era indivisa, sin una dicotomía entre un ello, por una parte, y un conjunto de yo y superyó, por la otra. Y puesto que en consecuencia nadie sentía que debía dominar a ciertos aspectos de sí mismo ni a otros seres humanos, ni que los humanos como un todo debían dominar al resto de la naturaleza, ni que se debía obtener un número mayor de bienes por medio de un trabajo indeseable "con el sudor de la propia frente", todas las sociedades humanas eran lo que el antropólogo Pierre Clastres $(1974,1987)$ Ilamó 'sociedades indivisas', sin gobernantes o gobernados, ricos o pobres, propietarios o no-propietarios, en las cuales la subsistencia era garantizada por actividades lúdicas. Así pues, todos parecían vivir en armonía, en base a una "economía de la abundancia", en la cual la carencia económica era prácticamente desconocida, por lo cual no se deseaba acumular bienes con el engañoso objetivo de "mejorar la vida"7. Marshal Sahlins afirma sin ambages que la pobreza fue inventada por la civilización ${ }^{8}$, mientras que comentaristas ácratas de Clastres como el Fernando Savater joven (1985/1987) señalan que es un grave error del marxismo el afirmar que las comunidades primitivas vivían en la indigencia pues no habían logrado desarrollar su economía.

La "evidencia" reunida por los antropólogos y etnólogos sugiere que la represión sexual y la represión hacia los niños (Service 1978 p. 81, Briggs 1998 pp. 4-5, Malinowski 1932 p. 17, Kleinfield 1994 p. 153, Liedloff 1989 p. 97, Hewlett 1991, DeMeo 1998, Taylor 2005 pp. 192$194)^{9}$, el dominio masculino sobre las mujeres (Gimbutas, 1982, 1989, 1997; Eisler, 1987, español 1989, a matizar en base a Radford-Ruether 1992), y el poder político y económico de unos sobre otros (Capriles, 1994, en base a múltiples trabajos) eran inexistentes en el paleolítico y lo son todavía en buena parte de las sociedades cazadoras-pescadorasrecolectoras - $\mathrm{e}$ incluso horticultoras tempranas- de nuestros días. Claro está, las observaciones de los antropólogos y etnólogos son descalificadas por el pensamiento "postmoderno", en particular desde que Jacques Derrida (1967) "deconstruyó" a Lévi-Strauss. Aunque estoy de acuerdo con la premisa escéptica y "postmoderna" según la cual las ciencias (y esto se aplica no sólo a ciencias sociales como la antropología y la etnología) no demuestran absolutamente nada (Capriles, 1994, 
2007a vol. III, 2007b), reconozco que, como observó Gregory Bateson (1990), las mismas sí pueden refutar teorías $^{10}$. Ahora bien, si aceptamos que ciertas observaciones científicas pueden refutar teorías, tendremos que concluir que en las últimas dos o tres décadas, la concepción de la historia como perfeccionamiento y "progreso" ha sido refutada por múltiples hallazgos de ciencias como la paleopatología, la etnoecología y la arqueología.

La primera de dichas ciencias, en investigaciones por todo el mundo, no ha hallado indicios de muertes por violencia ejercida por otros seres humanos antes del 4000 a.C. (Lochouarn 1993, van der Dennen 1995, DeMeo 1998, Taylor 2005), excepto en unos pocos sitios en el valle del Nilo a partir del 12.000 a.C. - lo cual contradice la imagen popular de los hombres de la edad de piedra dándole garrotazos a las mujeres para llevarlas a su cueva y matándose entre sí por su posesión-. La violencia entre los seres humanos, la represión sexual, la represión hacia los niños, el dominio sobre las mujeres y el poder político y económico de unos sobre otros parecen haber surgido de manera más o menos simultánea, originalmente en los desiertos del Norte de África y el Medio Oriente, así como en las regiones áridas del Cáucaso, que en su conjunto conforman lo que James DeMeo (1998) designó como Saharasia. A medida que los kurganes (actualmente conocidos como indoeuropeos), los semitas y otros pueblos "saharasiáticos" conquistaron el resto de Eurasia y buena parte de África, los vicios que los caracterizaban se generalizaron por esas regiones (Eisler, 1987, español 1989; Ceruti y Bocchi, 1994; DeMeo, 1998; Taylor, 2005). Algún tiempo después aparecieron fenómenos semejantes en América, comenzando por los desiertos mesoamericanos y del sur de Norteamérica y las regiones áridas del gran Perú.

Todo lo anterior sugiere claramente que los humanos del período preético exhibían en su comportamiento virtudes que los humanos del período ético han perdido totalmente, y que no sólo han perdido, sino que han remplazado con los vicios que constituyen sus contrarios -lo cual, como hemos visto, parece haberse debido a que en el paleolítico el psiquismo humano todavía estaba libre de las alienación ontológica y en consecuencia de las ilusorias divisiones y contraposiciones en la raíz de los conflictos humanos (lo cual era concomitante con el hecho de que todavía no habían surgido ni el Estado, ni la propiedad privada o colectiva, ni la pareja exclusivista en la cual cada parte posee a la otra y ambas poseen a los hijos). En otras palabras, la paleopatología sugiere que en el paleolítico todavía los seres humanos conservaban una condición similar a la del bíblico "Paraíso terrenal", la "edad de oro" grecorromana o lo que en India se llamó "era de perfección" (krityayu- 
ga) o "era de la Verdad" (satyayuga). Ahora bien, una vez que apareció la agresión contra los otros seres humanos y el resto de la ecosfera, dicha actitud se generalizó y agudizó progresivamente, hasta provocar la crisis ecológica que, según muchos científicos, si todo sigue como va, podría ocasionar la desintegración de la sociedad humana, así como la extinción de nuestra especie, durante el presente siglo. Como he señalado (1994), esta crisis representa la reducción al absurdo empírica de la alienación ontológica, que es la causa más profunda de los males aquí reseñados y de todo lo que se desarrolló con ella, demostrando que constituye un error que hace que no sea funcional, y exigiendo la superación tanto de ella misma como de todo lo que ella produjo - de la cual dependen la continuidad de la vida en el planeta y la restauración del orden primordial, de la no violencia, y así sucesivamente, rotos por el desarrollo de la alienación en cuestión.

\section{Los tipos de alienación y su desarrollo: alienación comunicativa y alienación consumista}

$\mathrm{E}$ n el III Foro Internacional de Filosofía, que tuvo lugar el año pasado en la ciudad de Maracaibo, enumeré y consideré varios de los múltiples sentidos del término alienación, incluyendo el ontológico ya considerado, el religioso (concomitante con el ontológico), el ecológico (concomitante con los dos anteriores), el político (que sigue poco después), el económico (que según pensadores ácratas sigue al anterior, pero que según el marxismo lo precede), el educativo, el eróticosexual, el mal llamado comunicativo, el de género, el consumista, etc. ${ }^{11}$. En este IV Foro, la Profesora Jacqueline Clarac de Briceño abordó de manera briIlante el problema de la alienación antropológica. Debido a la temática señalada para el presente Foro, después de la ya realizada discusión de la alienación ontológica, debo discutir brevemente la alienación comunicativa y la alienación consumista.

La comunicación resulta de la alienación ontológica, pues ella requiere un yo y un otro en nuestra experiencia, y, como ya se señaló, éstos surgen a raíz de la aparición de la alienación ontológica. Para discutir la alienación comunicativa debemos antes que nada recordar que, tomando el interés como criterio, J. Habermas clasificó la acción humana en acción instrumental, acción comunicativa y acción emancipadora. Para Habermas -quien parece seguir en esto una tesis de Engels ${ }^{12}$-, la acción instrumental debe caracterizar a las relaciones entre los seres humanos y la naturaleza, mientras que la acción 
comunicativa $(y$, siempre que ello sea necesario, la emancipadora) debe caracterizar a las relaciones entre seres humanos. En otros trabajos (Capriles, 1994, 2007b) he criticado esta tesis en términos que resumo en la nota cuyo Ilamado sigue inmediatamente ${ }^{13}$. En esta discusión del aspecto comunicativo de la alienación, es menester resaltar el hecho de que, a medida que se fueron inventando y perfeccionando medios para controlar el pensamiento, se fue resaltando cada vez más la importancia de la libertad de pensamiento; a medida que se fue desarrollando el germen de lo que sería la "ingeniería social", se fue poniendo cada vez más énfasis en el ideal "democrático" de libertad. No parece haber sido casualidad el que, justamente en la época en la que se desarrollaron los medios de difusión de masas - cuya estructura es unidireccional y cuya función es formar y manejar la opinión pública, inculcando en los miembros de la sociedad las opiniones que los dueños del capital creen de su conveniencia, aunque en verdad no lo son, ya que no es en el interés de nadie destruir a su descendencia por medio del consumo desenfrenado, y enseñándolos a recibir información que contiene órdenes implícitas o explícitas sin cuestionar las creencias y órdenes recibidas - se haya desarrollado el ideal de los "derechos humanos" $y$, en particular, el de los derechos a la libertad de pensamiento y a la libertad de expresión que esos me- dios nos impiden ejercer. En efecto, desde sus comienzos los ideales del liberalismo burgués no fueron más que un pretexto para que una clase se hiciera dominante y una fachada para ocultar un proyecto contrario a esos ideales, así como un medio para manejar a las masas a través del engaño y la contradicción por medio de lo que he llamado "doble constreñimiento normalizador"14. Habermas se ubicó en el campo del liberalismo capitalista al afirmar que la aparición de los medios de difusión de masas representó un avance de la acción comunicativa frente a la acción instrumental ${ }^{15}$, cuando en verdad desde sus comienzos esos medios han contenido la semilla del Brave New World (Un mundo feliz) temido por Aldous Huxley, en el cual se controlaría a los individuos y se los programaría para consumir, "desde la psiquis de éstos", sin permitir que percataran de que estaban siendo controlados y haciéndolos creer que al cumplir las órdenes recibidas estaban ejerciendo su libertad, aunque tanto las democracias burguesas como los mal Ilamados "socialismos reales" mezclaron elementos de la pesadiIla descrita por Aldous Huxley con elementos de la que Orwell plasmó en 1984, la praxis de las primeras parece haber tendido más hacia la primera y la de las segundas parece haber tendido más hacia la segunda. Es por todo esto que la tesis de McLuhan, según la cual el mundo se ha transformado en una aldea global, es un eufemismo destinado 
a inducir una valoración positiva del negativo fenómeno constituido por la universalización del manejo instrumental de las conciencias por los medios de difusión de masas. Este es un aspecto muy grave de la alienación, en la medida en que lo que lo que enajenamos es nuestra propia libertad, y como resultado de ello se nos conduce hacia la autodestrucción.

Finalmente, la alienación consumista no puede ser considerada separadamente de la alienación comunicativa, ya que son los medios de difusión de masas los que nos instigan al consumo. En efecto, en tanto que los medios en cuestión sigan haciendo creer a las masas que la plenitud sólo se alcanzará mediante la obtención de altísimos niveles de consumo, seguiremos destruyendo el ecosistema de manera cada vez más frenética y será imposible lograr la Revolución Total, que pondría fin a la alienación en todas sus variedades, y que gracias a ello haría posible tanto la supervivencia de la humanidad como la transición al comunismo -el cual sólo será posible si es como lo concibió Marx (1959) al afirmar que "el comunismo es la reconciliación (Versohnung) del hombre con la naturaleza": o sea, si es ecomunismo.

Por supuesto que el término reconciliación en este caso no debe entenderse en el sentido de Hegel, y ni tan siquiera de la manera como Marx reinterpretó dicho sentido, sino en el de superar la dualidad sujeto-objeto que parece separar la conciencia de lo que tomamos como un "medio ambiente", con lo cual se superaría la alienación ontológica y por lo tanto también la alienación religiosa que le es inherente, lográndose algo en parte equivalente a lo que el joven Marx designó como la "transustanciación de Dios en el comunismo". En efecto, los dioses surgieron como resultado de la alienación ontológica, pues una vez que nos hicimos incapaces de acceder al estado de Comunión en el que el mundo se vivencia como lo sagrado, tuvimos que proyectar esto último en un "más allá". Puesto que el fin de la alienación ontológica implica redescubrir lo sagrado en nuestra dimensión, el mismo nos hará reintegrarlo, con ello reintegrando a los dioses.

La condición que precede a la aparición de los dioses es ilustrada por el contenido del arte del paleolítico superior, que para LeroiGourhan (1965) era una expresión religiosa basada en la relación de los sexos, y que para etnólogos como Cauvin (1987) y Lommel (sin fecha) reflejaba una espiritualidad "horizontal", la cual para Cauvin era no-teísta, recordando el yin-yang chino: no hay algo más allá del mundo y por encima de los seres humanos a lo cual éstos deban rendir culto. Todavía no ha ocurrido en el Próximo Oriente y antes del comienzo del neolítico, el "nacimiento de los dioses". Cauvin (1987) escribe: 
Aunque se sabe que el sentimiento religioso acompaña a la especie humana desde hace mucho tiempo, no es fácil, en cambio, fechar la aparición de los primeros dioses. El arte paleolítico poseía ya un contenido "religioso", pero parece no tener referencia a dioses. La noción de divinidad se manifiesta por primera vez en el Cercano Oriente en forma de estatuillas femeninas en terracota, en el comienzo mismo de la "revolución neolítica", un momento muy importante de la historia de la humanidad. Precediendo por poco tiempo a los primeros experimentos agrícolas, esta mutación psíquica podría explicar en parte la formidable transformación del neolítico.

Yo prefiero decir que el arte del paleolítico expresa la visión de Comunión, que para ese entonces probablemente se manifestaba ya únicamente durante el rito. Cauvin habría ubicado un momento clave en la "caída": aquél en el cual se deja de representar el mundo como divino y comienza a representar- se lo sagrado fuera del mundo, como una diosa-madre con una profunda y poderosa mirada, y un dios-toro. Con esto, lo sagrado se habría proyectado en un imaginario plano supramundano, en el cual se mantendrá por largo tiempo. Cauvin (1987) nos dice:

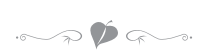

El arte refleja allí, aparentemente, un evento de carácter psíquico. Lo sagrado ya no está a nivel del hombre, sino "por encima" de él. Esto se traduce en la creencia en una entidad suprema, que puede tener forma humana o animal, mientras la humanidad de aquí abajo estará en adelante volcada hacia ella por el esfuerzo de la oración, que expresan los brazos elevados hacia el cielo...

No sólo es entonces la Diosa la primera instancia suprema en forma humana - o sea, que el origen y la supremacía del mundo natural es concebido por el hombre, por vez primera, "a su imagen y semejanza", incluyendo el poder psíquico que expresa la "mirada" de las estatuillas-, sino que el plano divino es aquél en el cual los contrarios se juntan y las tensiones se resuelven..." 
El mundo y los seres humanos que son parte de él pierden su carácter sagrado, y lo divino es personalizado y proyectado en un "más allá", en el cual permanecerá durante el transcurso de la historia - hasta que la reducción al absurdo del error humano básico haga posible su disolución en la patencia de la plenitud de lo dado, restableciendo el estado de Comunión y haciendo que el mundo físico se redescubra como lo divino, resacralizándose-. Esto es lo que el joven Marx Ilamó la "transustanciación de Dios en el comunismo", pero que para mí constituiría la aparición de lo suprahumano (aunque no como lo concibieron, cada cual a su manera, Nietzsche, Teilhard o Aurobindo) y que haría posible la ya considerada "reconciliación del ser humano con la naturaleza", impidiendo que se dominase a otros seres humanos y el resto de la naturaleza, restableciendo así el comunismo a un nuevo nivel, y devolviéndonos la plenitud y la total ausencia de dominio y explotación que son inherentes al estado que he llamado "de Comunión". En efecto, sería la generalización del estado de Comunión lo que haría posible la restauración del comunismo, y la restauración del comunismo es lo que haría posible que todos pudiésemos mantenernos en el estado de Comunión, pues Comunión y comunismo son concomitantes, en la medida en que ambos conllevan la erradicación de lo relacional. De modo que ninguno de los dos puede generalizarse si no lo hace también el otro. En todo caso, serían la generalización del estado de Comunión y la concomitante restauración del comunismo las que harían posible nuestra supervivencia como especie y la materialización de lo que hasta ahora había sido la utopía - con lo cual haría el mundo volvería a ser un "buen lugar" (eu-topos).

Ahora bien, para que la restauración tanto de la Comunión como del comunismo sea posible, es imprescindible una praxis verdaderamente efectiva para erradicar la alienación ontológica correspondiente al ser-para-Sí que es inherente al error o delusión Ilamado lethe o avidya. De eso me he ocupado parcialmente tanto en el artículo "¿El ecosocialismo como vía hacia el ecomunismo?" (Capriles, 2007c) como en el libro Individuo, sociedad, ecosistema (Capriles, 1994).

\section{ReferenCias}

Bateson, Gregory. Conscious Purpose Versus Nature. En: The Dialectics of Liberation, 34-49. Cooper, David (Ed.). Pelican Books. Harmondsworth, Middlesex, Inglaterra.1968.
Bateson, Gregory. Steps to an Ecology of Mind. Ballantine Books Nueva York, EE.UU. 1972.

Espíritu y naturaleza. Amorrortu editores S.A. Buenos Aires. 1990. (1a. Ed. española 1982). 
Besson-Girard, J.C. Decrescendo cantabile: Petit manuel pour une décroissance harmonique. Parangon. París. 2005.

Bocchi, Gianluca y Mauro Ceruti. El sentido de la historia (Origini di storie). Debate, colección Pensamiento. Madrid, Editorial. 1994, pp. 42-44. (Original italiano 1993.)

Briggs, J. L. Never in Anger. Harvard University Press. Cambridge, Mass., EE.UU. 1970.

Capriles, Elías. "La inversión hegeliana de la historia". Mérida, Venezuela: Filosofía (Revista del Postgrado de Filosofía, Facultad de Humanidades y Educación, Universidad de Los Andes), No. 4, 1992, pp. 87-105. Disponible en Internet en la URL http://www.webdelprofesor.ula.ve/humanidades/elicap/

. Individuo, sociedad, ecosistema: Ensayos sobre filosofía, política y mística. Mérida: Consejo de Publicaciones de la Universidad de Los Andes. 1994. Versión en proceso de corrección para una segunda edición disponible en Internet en la URL http://www.webdelprofesor. ula.ve/humanidades/elicap/

-_—— Beyond Mind, Beyond Being, Beyond History: A Dzogchen-Founded Metatranspersonal, Metapostmodern Philosophy and Psychology for Survival and an Age of Communion. En tres volúmenes: Volumen I: Beyond Being: A Metaphenomenological Elucidation of the Phenomenon of Being,
The Being of the Subject and the Being of Objects. Volumen II: Beyond Mind: A Metaphenomenological, Metaexistential Philosophy, and a Metatranspersonal Metapsychology. Volumen III: Beyond History: A Degenerative Philosophy of History Leading to a Genuine Postmodernity. 2007a. Internet: Moscú: (http:// www.eliascapriles.dzogchen.ru/ y Mérida, Venezuela (versión corregida) http://www.webdelprofesor.ula. ve/humanidades/elicap/ Hacia el ecomunismo: una respuesta mítica a algunos problemas del marxismo. San Salvador: Realidad: Revista de Ciencias Sociales y Humanidades, 112 (correspondiente a abril-junio 2007), pp. 271-308. Disponible en Internet en la URL http://www.webdelprofesor. ula.ve/humanidades/elicap/

ecosocialismo como vía hacia el ecomunismo? Una propuesta pragmática. Mérida, Venezuela: Humania del Sur, 2:1, 2007c, pp. 85-125. Disponible en la URL http://www.webdelprofesor. ula.ve/humanidades/elicap/

Cauvin, Jacques. L'apparition des premières divinités. La Recherche, 195, 1987, pp. 1472-1481.

Naissance des divinités, naissance de l'agriculture. Flammarion. París. 1998.

Clastres, Pierre. La société contre l'état: Recherches d'anthropologie politique. Les Éditions de Minuit. Paris. 1974.

abundancia en la sociedad indivisa. 
(Originalmente publicada como prefacio a la obra de Marshall Sahlins Stone Age Economics.) Testimonios, 4 (suplemento). 1987. (Reproducido a partir de: Aletheya, 6 [suplemento]).

Dale, Tom \& Carter, Vernon Gill. Topsoil and Civilization. University of Oklahoma Press. Oklahoma, OK. 1955.

DeMeo, James. Saharasia. Natural Energy Works. Ashland, OR: 1998.

Derrida, Jacques. La voix et le phénomène. Introduction au problème du signe dans la phénoménologie de Husserl. Presses Universitaires de France. Paris 1967.

Descola, Philippe (1996). "Les cosmologies des indiens d'Amazonie. Comme pour leurs frères du nord, la nature est une construction sociale". París: La Recherche, 292, noviembre 1996, 62-7. Eisler, 1987, español 1989

De Benoist, Alain. Demain, la décroissance! Penser l'écologie jusqu'au bout. Éditions Édite. París. 2007.

Dulbecco, P. y Garroustedans, P. «Nicholas Georgescu-Roegen ou l'invention de la bioéconomie». En Problèmes économiques, enero 2005, pp. 41-48. 2005.

Dupuy, J.-P., Acevedo, H. y Robert, J. La traición de la opulencia. Gedisa. Barcelona, España. 1979.

Elwin, V. The Kingdom of the Young. Oxford University Press. Bombay, India. 1968.
Ferrari, Vincenzo. Danilo Zolo, La teoria comunista dell'estinzione dello Stato (nota bibliográfica). Crítica Jurídica, 1, Puebla, México. 1984, p. 69.

Fetscher, Iring (1967; español, 1971), Carlos Marx y el marxismo. Caracas: Monte Ávila Editores. Fromm, Erich (1947). Man for himself: An inquiry into the psychology of ethics. Nueva York: Rinehart \& Company.

Gimbutas, Marija. Goddesses and Gods of Old Europe, 7000 to 3500 B. C.: Myths, Legends, and Cult Images. University of California Press. Berkeley, CA. 1982.

. Il linguaggio della dea. Mito e Culto della dea madre nell' Europa neolitica. Longanesi, Milan. 1989.

. The Civilization of the Goddess. HarperSanFrancisco. San Francisco, CA. 1991.

. The Living Goddesses. University of California Press. Berkeley, CA. 1997.

Guastini, Riccardo. "Sobre la extinción del Estado (un enfoque analítico)". Crítica Jurídica, 1. Puebla, México. 1984.

Hegel, G. W. F. Fenomenología del espíritu. Fondo de Cultura Económica. México. 1966 (Original alemán 1807).

Heidegger, Martin (1943). Aletheia. En Heidegger, M. (1975). Early Greek Thinking, 102-123. 
Nueva York, EE.UU.: Harper \& Row Publishers.

Ser y tiempo. Traducción de José Gaos. Fondo de Cultura Económica. México. 1971 (Original alemán 1927; 1a ed. española 1951).

Hewlett, B. S. (1991). Intimate Fathers: The Nature and Context of Aka Pigmey Paternal Kleinfield 1994

Illich, I. Deschooling Society. Harper \& Row. Nueva York. 1971. Utilizamos la versión francesa (1971), Une société sans école. Paris, Éditions du Seuil.

- Toward a History of Needs. Pantheon Books. Nueva York. 1977.

Kleinfield, J. (1994). Learning Styles and Culture. En Lonner, W. J y Malpass, R. (comp.). Psychology and Culture. Boston, Mass., EE.UU.: Allyn and Bacon.

Laing, Ronald D. (1961). The Self and the Others. London: Tavistock. (Paperback 1969. Self and Others. Harmondsworth, Middlesex, UK: Pelican.)

Latouche, Serge Faut-il refuser le développement? PUF. Paris. 1986. ce. Ed. Fayard. París. 2006.

Lawlord, R. (1991). Voices of the First Day. Awakening in the Aboriginal Daytime. Rochester, VT, EE.UU.: Inner Traditions.
Leroi-Gourhan, André. Préhistoire de l'art occidental. Lucien Mazenod. París. 1965.

Liedloff, J. The Continuum Concept. Arkana. Londres. 1989.

Lochouarn, Martine «De quoi mouraient les hommes primitifs». Sciences et Avenir, 553, 1993, pp. 44-47.

Lommel, Andreas (sin fecha). "El arte prehistórico y primitivo". En El mundo del arte: Las artes plásticas de sus orígenes a la actualidad, Vol. I. Brasil (no se indica la ciudad): Aggs Industrias Gráficas S. A.

Malinowski, B. The Sexual Life of Savages. Routledge \& Kegan Paul. Londres. 1932.

Marx, Karl El capital. Fondo de Cultura Económica. México. 1959.

- Manuscritos: Economía y filosofía. Alianza Editorial, El Libro de Bolsillo Madrid. 1970. (1a Ed. en esta colección 1968).

SARPE. Madrid. 1984.

Marx, Karl y Engels, Friedrich (1999). Manifiesto del Partido Comunista. Internet: http://www.marxists. org/espanol/m-e/1840s/48-manif. htm (ed. original 1848).

Mead, Margaret. Coming of Age in Samoa: A Study of Adolescence and Sex in Primitive Society. Mentor Books. Nueva York. 1960.

Mollat, M. The Poor in the Middle Ages. An Essay in Social 
History. Yale, New Haven, EE.UU. 1978. Citado en Rahnema, Majid (2007).

Popper, Karl R. The Logic of Scientific Discovery. Science Editions, Inc. New York. 1961. (Original Ed. 1959.)

Radford-Ruether, Rosemary Gaia \& God: An Ecofeminist Theology of Earth Healing. Harper San Francisco. New York. 1992.

Rahnema, Majid (2007). "Eradicating Poverty or the Poor?" En Kumar, Corinne, Asking, we Walk, vol. I, pp. 22-31. Bangalore, Madhya Pradesh, India: Streelekha Publications [Publication Unit of CIEDS Collective]).

Sahlins, Marshall (1961). Evolution and Culture. Ann Arbor, MI: The University of Michigan.

Social Stratification in Polynesia. University Of Washington Press. Seattle. 1972.

_- Stone Age Economics. Tavistock Publications. London. 1974.

\section{Culture and Practical}

Reason. University of Chicago Press. Chicago. 1976.
Sartre, Jean-Paul. L'être et le néant. Essai d'ontologie phénoménologique. NRF Librairie Gallimard. Paris, 1980. (31 edición.)

Savater, Fernando (1985/1987). Pierre Clastres. En Clastres (1987).

Service, E. R. Profiles in Ethnology. Harper \& Row. Nueva York. 1978.

Taylor, Steve (2008). La caída: Indicios sobre la edad de oro. La historia de seis mil años de locura y el despertar de una nueva era (prefacio de Elías Capriles). Vitoria, España: Ediciones La Llave. (Original en inglés 2005.)

Van der Dennen, Johan M. G. The Origin of War: The Evolution of a Male-Coalitional Reproductive Strategy. Origin Press. Groningen. 1995.

Weisskopf, Walter. Alienation and Economics. Dutton. Nueva York. 1971.

Yapa, L. (1996). What Causes Poverty? A Postmodern View. En Annals of the Association of American Geographers. Citado en Rahnema, Majid (2007).

Zolo, Danilo La teoria comunista dell'estinzione dello stato. De Donato. Bari, Italia. 1974. 
NOTAS

1 Lo anterior ha sido interpretado de maneras diversas, y entre estas interpretaciones podemos distinguir entre un extremo subjetivo o subjetivista, según el cual la alienación es primariamente la del ser humano individual, $\mathrm{y}$ un extremo objetivo u objetivista, según el cual el ser humano, y en particular el trabajador, es alienado de sus productos por los mecanismos que gobiernan la sociedad. Esta última es la interpretación más aceptada y la que mejor cuadra con las tesis del Marx maduro plasmadas en Das Kapital, como diferente de las del Marx joven, que es el que ha sido considerado como humanista, existencial, o preexistencial. En todo caso, el concepto marxiano de alienación o enajenación es una reinterpretación en gran medida económica del término hegeliano Entfremdung, que Marx introdujo en los Manuscritos económicos y filosóficos de 1844.

Esta interpretación marxiana fue desarrollada por Erich Fromm (1947, pp. 62-81), quien distinguió cuatro orientaciones básicas de caracteres no productivos autoalienados: la receptiva, la acaparadora, la explotadora y la de mercado, entre las cuales las tres primeras se originaron en épocas anteriores y fueron heredadas por nosotros, mientras que la cuarta es un producto moderno.

2 Danilo Zolo (1974), entre otros, ha afirmado que la doctrina marxista de la extinción del Estado no tiene su origen en Marx sino en Engels, y que sólo Lenin la desarrolló en profundidad. Vincenzo Ferrari (1984) ha criticado este punto de vista. Riccardo Guastini (1984), por su parte, afirma que dicha doctrina aparecerá como tal en Marx si sometemos sus escritos al análisis del lenguaje. En todo caso, hay referencias directas a la doctrina en cuestión en Marx (1984), y en Marx y Engels (1999).

El conocido manifiesto A Blueprint for Survival (Equipo Editorial de la revista The Ecologist, 1971) - el cual se apoyó en un documento suscrito por los científicos más notables del Reino Unido y por organizaciones tales como The Conservation Society, Friends of the Earth, The Henry Doubleday Research Association, The Soil Association y Survival International_, afirmaba:

"Un examen de la información relevante asequible nos ha hecho tomar conciencia de la extrema gravedad de la situación global en nuestros días. Pues, si permitimos que persistan las tendencias imperantes, la ruptura de la sociedad y la destrucción irreversible de los sistemas que sostienen la vida en este planeta, posiblemente hacia el final del siglo (XX), sin duda dentro de la vida de nuestros hijos, serán inevitables”.

A su vez, Michel Bosquet (en Senent, Saint-Marc y otros, 1973) advertía hace ya varias décadas que:"La humanidad necesitó treinta siglos para tomar impulso; le quedan treinta años para frenar antes del abismo".

Arturo Eichler (en una comunicación personal) ha afirmado que sólo una transformación total inmediata podría quizás hacer posible nuestra supervivencia, más allá de la primera mitad del presente siglo. Por su parte, Lester Brown (1990), del Worldwatch Institute en Washington, D. C., afirmó en el Foro Global sobre el Medio Ambiente y el Desarrollo para la Supervivencia 
que tuvo lugar en Moscú del 15 al 19 de enero de 1990, que "si no podemos invertir algunas de (las) tendencias (imperantes) en el futuro próximo, corremos el riesgo muy real de que la degradación ambiental pueda producir ruina económica, como ya lo ha hecho en partes de África, y de que las dos puedan comenzar a alimentarse mutuamente, haciendo cualquier progreso futuro extremadamente difícil... para el año 2030, o bien habremos producido un sistema económico mundial ambientalmente sostenible, o habremos fracasado claramente $y$, mucho antes de eso, la degradación ambiental y la ruina económica, alimentándose mutuamente, habrán llevado a la desintegración social. Lo haremos para el 2030 o habremos fracasado claramente".

En el siglo pasado, para mucha gente éstas eran predicciones alucinadas, pero ya en nuestro siglo organismos internacionales como la ONU y los medios de difusión de masas no pueden ocultar la gravedad de nuestra situación, y los comités científicos reconocen la extrema gravedad, no sólo del cambio climático que es ya abiertamente experimentado por todos, sino del desequilibrio de la totalidad de las variables del ecosistema tierra. Por lo tanto, advierten que nos quedan muy pocos años para implementar la transformación radical que haría posible nuestra supervivencia.

4 Para conocer mi reinterpretación de la avidya del Buda y la lethe de Heráclito como siendo lo mismo, cf. Capriles (2007a, vol. I), donde contrasto a profundidad mi interpretación de la lethe con las que están implícitas en las sucesivas in- terpretaciones de la aletheia que dio Heidegger (la del $\mathbb{S} 44 \mathrm{~B}$ de Sein und Zeit y la del texto de 1944 titulado Aletheia).

5 Para Hegel, la naturaleza, o el universo "material", era la proyección aparentemente externa de la idea, o del espíritu, etc., y se regía por las mismas leyes que el espíritu/la idea (con lo cual obliteraba la esencial distinción entre el mapa digital y el territorio analógico, que es insuperable en la medida en que debido a la incompatibilidad entre estos dos códigos los mapas conceptuales no pueden corresponder exactamente al territorio que interpretan). Por lo tanto, todo cambio en la naturaleza o el universo "material" debía implicar la negación del estado inmediatamente anterior. Ahora bien, Hegel quería demostrar que había progreso, por lo cual necesitaba una negación que no fuese como la negación lógica, pues de otro modo la negación de la negación nos devolvería al estado anterior a la primera negación y el progreso sería imposible. Fue por esto que ideó una negación que incorporaba la negación anterior en vez de deshacerla, y que al incorporarla daba lugar a mayor verdad y completud: la Aufhebung o "superación". Sin embargo, esta negación no se encuentra en proceso alguno; la única negación existente que es distinta de la negación lógica es la que he designado como negación fenomenológica y que es la que interviene en lo que Sartre (1980) llamó mala fe y que Laing (1961) designó como elusión y explicó en términos de una "espiral de simulaciones", la cual origina mayor falsedad y fragmentación. Cfr. Capriles (1992, 1994, 2007a vol. III). 

no "Gnitividad" corresponde a las cuatro últimas sílabas de la palabra "cognitividad". En ambos casos se eliminó el prefijo “co” porque implica la dualidad sujeto-objeto, mientras que lo que llamo Gnitividad es no-dual. En efecto, como señaló el poeta francés Paul Claudel, el 'conocimiento' (connaissance) es el 'co-nacimiento' (co-naissance) del sujeto [mental] y el objeto: es la dualidad sujeto-objeto lo que representa el prefijo "co". Nuestra Gnitividad puede compararse con un espejo, no en base a un modelo pasivo del conocimiento, sino porque en ella aparecen todos los fenómenos, sin encontrarse a una distancia de ella. En el estado que llamo "de Comunión” se manifiestan los fenómenos sin que una conciencia dualista se experimente como estando a una distancia de ellos. Mientras que en la condición dualista propia de la alienación ontológica, en la Gnitividad que ilustra el espejo se manifiesta también la conciencia dualista, que es un fenómeno constituido por el tipo de energía que constituye el pensamiento, y que no se halla a una distancia de lo que representa el espejo, no ocupa espacio alguno y no tiene forma ni color, pero sí parece encontrarse a una distancia de los fenómenos que aparecen como objeto. Alternativamente, podríamos ilustrar lo que llamo Gnitividad con una pantalla LCD, pero con ello nos iríamos al extremo contrario: mientras que el espejo parece implicar la existencia de una realidad externa al mismo que se refleja en él, la pantalla LCD parece implicar la no existencia de una realidad externa a ella, por lo cual el primero parece

implicar un modelo realista o por lo menos materialista, mientras que el segundo parece implicar un modelo idealista o incluso solipsista. Puesto que en nuestra época no se considera permisible asumir la existencia o inexistencia de una realidad externa a la experiencia que sea la base de la misma, mi explicación parte de la epojé fenomenológica, por lo cual no afirma ni niega la existencia o inexistencia de algo externo a nuestra experiencia que sea la base de la misma, sino que se ocupa de los fenómenos que se manifiestan en dicha experiencia: es por todo esto que se señala que los fenómenos que aparecen como objeto no se hallan a una distancia de la Gnitividad que se ilustró con el espejo.

Dejemos a un lado por un momento la epojé fenomenológica para discutir la concepción de Sartre desde el punto de vista del sentido común. Para Sartre, el Si-mismo no comprendía la dualidad entre ser-para-Si y ser-en-sí, sino que constituía una totalidad que los comprendía a ambos y que, a diferencia del serpara-Sí, era idéntica consigo misma. Puesto que tanto el pensamiento y la experiencia humana en general, por una parte, como los fenómenos del mundo que llamamos "material", por la otra, no son otra cosa que formas dinámicas del constituyente básico de la realidad que Einstein expresó con la fórmula $\mathrm{e}=\mathrm{mc}^{2}$, nada más apropiado que el continuo de energía que para Einstein era el universo para ilustrar el Si-mismo de Sartre. Si mantenemos la epojé fenomenológica esto no cambia, pues tanto nuestra experiencia del pensamiento como la del "mundo material" estarían constituidos por la "energía” (por así decir) de la Gnitividad que ilustré con el espejo. 
de Gnitividad no-dual y cuando en términos de la física hablamos del continuo de Einstein.

La aparición de la conciencia dualista es lo que da lugar al ser-para-Sí, que por su propia naturaleza queda automáticamente alienado del Sí-mismo, pues ella se experimenta como estando a una distancia de todo lo que aparece como objeto y en particular del "mundo material" — lo que Sartre llama ser-en-sí- y cree ser la fuente de sus actos y decisiones, y como tal no ser una función de la Gnitividad no dual. Desde entonces, a través de todos sus actos, el serpara-Sí trata de alcanzar la identidad consigo mismo y la totalidad que constituye el Sí-mismo, pero puesto que con cada uno de sus actos se afirma como un ente separado que actúa y que se encuentra separado del Sí-mismo que trata de alcanzar, se mantiene alienado como ser-paraSí y jamás alcanza el Sí-mismo.

Esta alienación ontológica constituiría el verdadero sentido de la alienación como la entendió $\mathrm{He}$ gel, pero que este último explicó erróneamente de manera idealista, abstracta y metafísica como el aparente dejar de ser espíritu o idea, por parte del espíritu o idea (etc.), y de manera igualmente errónea afirmó que la misma era subsanable sin que ello implicara la disolución de la dualidad sujeto-objeto. Sartre, en cambio, dejó bien claro que el Sí-mismo como holón sólo podría ser alcanzable por medio de la disolución del ser-para-Sí y por ende de la separación de éste con respecto al ser-en-sí —aunque consideró que en la práctica sería imposible la manifestación de este Sí-mismo como holón-. Mi diferencia principal con 
Sartre es que yo afirmo que el holón, que corresponde al estado de Comunión, sí puede manifestarse, y que deberá hacerlo al final de la historia para hacer posible tanto nuestra supervivencia como la transición al comunismo - las cuales van de la mano la una con la otra, ya que la supervivencia sólo será posible en el comunismo. Esto es lo que exige la crisis actual, y, en efecto, o alcanzamos el holón y con éste la transición al comunismo, $u$ ocasionamos nuestra extinción.

7 Refiero al lector a las obras de Pierre Clastres mencionadas en la bibliografía y al libro de Marshall Sahlins también allí mencionado.

8 Como lo muestro en Capriles (1994), ésta es la visión de las tradiciones de la "filosofía perenne", así como de pensadores de fines del siglo XX, tales como Iván Illich (1971, 1977) y Walter Weisskopf (1971). Es también la visión de Nicholas Georgescu-Roegen (Dulbecco y Garroustedans, 2005), de miembros de la escuela francesa del decrecimiento como Alain De Benoist (2007), Serge Latouche (1986, 2006) y J.-C. Besson-Girard (2005), y de pensadores como L. Yapa (1996), M. Mollat (1978), M. Rahnema (2007), Dupuy, Acevedo y Robert (1979), etc. (Jean Robert colaboró con Ivan Illich en Cuernavaca, México.)

9 Los autores citados proporcionan mucha evidencia de ausencia de represión hacia los niños, como lo hacen también muchos otros autores. Lawlor (1991) nos la ofrece con respecto a los aborígenes australianos. Y si bien un antropólogo australiano trató de demostrar que Margaret Mead (1960) había falseado los he- chos al describir a Samoa como un paraíso de la libertad sexual, las observaciones de este último tuvieron lugar luego de que la afluencia de extranjeros modificara las actitudes de los nativos en múltiples ámbitos (un cambio que yo pude observar en otros respectos entre los refugiados tibetanos en Nepal: cuando llegué a ese país en 1973, todos los tibetanos con quienes me cruzaba me saludaban con signos tradicionales de respeto mientras sonreían y me dispensaban las miradas más luminosas que recuerdo; pocos años después esto ya no sucedía, y en cambio ya había un cierto número de jóvenes tibetanos adictos a la heroína que trataban de sustraerle a uno sus posesiones).

Uno de los ejemplos más notables de libertad sexual y ausencia de represión hacia los niños es los dormitorios de niños entre los trobriandeses y los muria, en los cuales estaba prohibida la entrada de los adultos y en los cuales los niños podían escoger distintas parejas para relaciones sexuales sin interferencia paterna (Taylor, 2005, p. 193); lo más interesante de esto es que los anticonceptivos naturales que usaban los Muria eran tan efectivos que mucho menos de $2 \%$ de las niñas habían sido fecundadas a los 16 años, después de pasar un buen número de años en dichos dormitorios (Elwin, 1968). Esto coincide con la tesis que Jacques Cauvin cree haber demostrado, según la cual las transformaciones díscolas de nuestra especie a lo largo de su desarrollo filogenético no se debieron a la presión demográfica; esta última podría ser el resultado del abandono de los anticonceptivos naturales por influencia de las religiones de los 


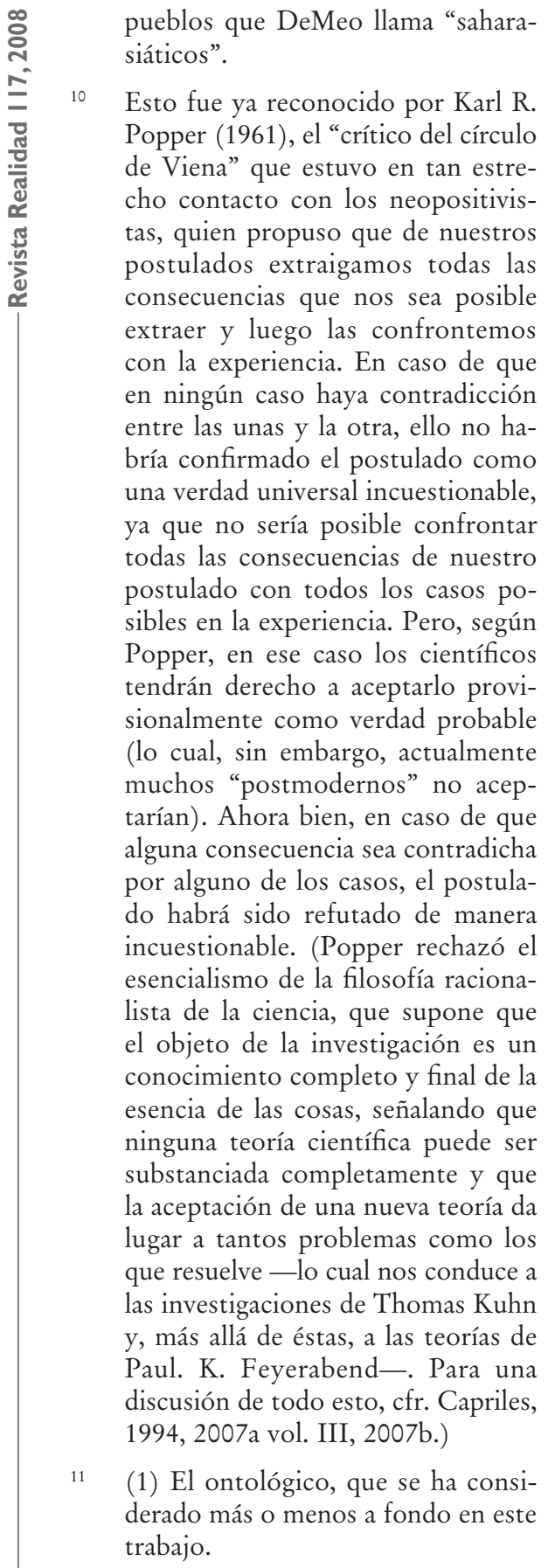

(2) El religioso. Sartre equiparó el Sí-mismo o el holón con Dios, por lo menos hizo coincidir sus respectivas definiciones; de modo que podríamos decir que Dios es una consecuencia de la alienación del para-sí con respecto al Sí-mismo. Por lo tanto, esta alienación no es en ningún sentido diferente de la alienación en el sentido ontológico; sin embargo, quizás sería más preciso decir que la alienación religiosa es consecuencia de la alienación en el sentido ontológico, que decir que es lo mismo que ella. En efecto, como se verá al discutir la religión al final de esta ponencia, es cuando la alienación ontológica ha roto ilusoriamente la totalidad originaria que (somos), que proyectamos un dios en un más allá supramundamo o transuranio.

(3) El ecológico. Sartre jamás equiparó el Sí-mismo con la physis de Heráclito y de los filósofos jonios en general, aunque sí afirmó que implicaba la superación (en un sentido no hegeliano del término) de la discontinuidad entre ser-para-Sí y ser-en-sí, de modo que comprendería tanto nuestra Gnitividad (o sea, la Gnosis no dual que sirve de base al conocimiento dualista y a la desaparición de este último en el estado de Comunión) como la totalidad de lo que normalmente aparece como objeto, y, por lo tanto, en su formulación estaba implícita la concepción del Sí-mismo como algo que comprende la totalidad de la naturaleza y de lo que llamamos " $f$ ísico". En todo caso, mi redefinición de dicho Sí-mismo (lo cual hice con mayor precisión en Capriles, 2007a vol. I, cap. IV), deja bien claro que el Sí-mismo puede equipararse a la physis. 
De una forma u otra, el Sí-mismo es la totalidad que somos, y de la cual nos alienamos ilusoriamente cuando se manifiesta el ser-para-Sí, y esta totalidad, que comprende tanto a la conciencia dualista concomitante con el ser-para-Sí, como a todos los elementos de la naturaleza que se manifiestan como ser-en-sí (o en mi terminología como ser-que-es-en-sípara-el-ser-para-Sí), es precisamente aquello que los jónicos y en general los presocráticos designaron como physis, y que comprende al oikos. Esto implica que la alienación ontológica conlleva la alienación con respecto a la naturaleza en general, en el sentido de physis, y por lo tanto también con respecto al oikos, lo cual hace que en ella se halle la raíz primera de la crisis ecológica y del proyecto consciente contra la naturaleza (Bateson, 1972) —aunque estos últimos se desarrollan mucho más tarde que la alienación primera, que es la ontológica, y como consecuencia de ella. (Lo anterior es una forma simplificada de expresar esta alienación, pues según la enseñanza dzogchén la alienación con respecto al Sí-mismo está manifiesta incluso antes de la manifestación del serpara-Sí, pues en los seres que sienten que no han reGnoscido su verdadera condición la avidya ha estado desde siempre manifiesta en el primero de los sentidos que las distintas clasificaciones de la enseñanza dzogchén dan al término, que es el de ignorancia de nuestra verdadera condición.)

(4) El político, que puede dividirse en (4a) macropolítico y (4b) micropolítico. Éste se desarrolla mucho más tarde, y no es posible determinar que sea anterior al económico, ya que hay una importante divergencia de opinión entre los marxistas y los bönpos (adherentes de la religión tibetana prebudista), por una parte, que afirman que el poder macropolítico es una consecuencia de la aparición de la propiedad privada, destinado a protegerla, y el pensamiento ácrata, por la otra, que sugiere que la propiedad es una consecuencia del poder político - como ha creído demostrarlo Marshal Sahlins con sus estudios sobre las monarquías polinesias-. En todo caso, el poder político es una consecuencia de la aparición de los dioses en un más allá supramundano, que establece una relación vertical en la psiquis humana entre un principio dominante que se encuentra arriba y otro dominado que se encuentra abajo, la cual se reproduce en el plano macropolítico entre gobernantes y gobernados y en el plano micropolítico entre padres e hijos, o entre adultos y menores en general (en las sociedades llamadas "primitivas" no existe el dominio sobre los hijos; cf. Taylor, 2005). Esto lo he discutido repetidamente en otros trabajos (Capriles, 1994, 2007a vol. III, 2007b, 2007c, etc.).

(5) El económico. En este plano tenemos una primera alienación marcada por la aparición de la propiedad privada (el individuo se separa de la tierra y/o de otros aspectos del universo y los posee), y una segunda marcada por la aparición del trabajo alienado, que es la alienación en el sentido marxista clásico.

(6) El educativo. Este es un aspecto y una extensión (según el caso) de la alienación micropolítica, pues se trata de la imposición de contenidos educativos y por lo tanto de un adoctrinamiento ideologizante sobre los infantes. 
(7) El erótico-sexual. Se trata en este caso de la alienación, en sociedades civilizadas, del erotismo o según dicen algunos (imprecisamente según Foucault) la sexualidad, al reprimirla y confinarla a lo genital. Lo eróticosexual no alienado es polimorfo; fue por ello que el perverso Freud caracterizó lo erótico-sexual polimorfo como perverso.

(8) El mal llamado comunicativo. Es el que introducen quienes ostentan el poder luego de que surgen las relaciones verticales y que luego reproducen los medios de difusión de masas, que impide la comunicación en la medida en que lo que hay es un productor y un receptor de mensajes unidireccionales, lo cual en contra de la tesis de Habermas niega la esencia misma de la comunicación.

(9) El consumista, que consiste en tratar de llenar en vacío que surge de la alienación ontológica - pues la ruptura de la totalidad en nuestra experiencia produce una carencia de totalidad, mientras que la ilusoria separación de nuestra mente con respecto al continuo ininterrumpido que para Einstein es el universo nos hace experimentar la carencia de la plenitud de dicho continuo- por medio del uso de bienes y servicios que experimentamos como intrínsecamente externos a nosotros, con lo cual consumimos el mundo, destruyendo el ecosistema.

(10) El de género.

Etc.

12 En Fetscher, Iring, 1967; español 1971, podemos leer: "En la sociedad sin clases, que Marx considera como la etapa final de la evolución social, desaparecen conjuntamente el problema del Estado y el problema de la burocracia. Entonces ya no habrá ningún dominio del hombre sobre el hombre y - -según un dicho de Engels, que se remonta a fuentes más antiguas - en lugar de dominar sobre las personas se dominarán las cosas. Marx en El capital admite repetidamente que, como es obvio, también en esta sociedad sin clases se seguirá dando una cierta dosis de subordinación y de autoridad, pero se tratará de relaciones objetivamente condicionadas y racionalmente fundadas, que Marx, evidentemente, considera compatibles con una total libertad.”

13 Al proponer esto, Habermas ignora dos importantes realidades. (1) Antes que nada, ignora que, puesto que el proceso secundario (asociado al hemisferio cerebral izquierdo) funciona sobre la base del proceso primario (asociado al derecho), al intentar determinar la experiencia y la conducta del ser humano debe enfrentar las limitaciones que le impone el código del proceso primario, lo cual hace que sus intentos de controlar dicha experiencia y dicha conducta a menudo produzcan efectos no deseados e insospechados. Una vez que se desarrolla un tipo de relaciones de proceso primario - como ha sucedido cada vez más con las instrumentales en los últimos milenios-y éstas comienzan a ganar terreno en todos los campos, no es posible detener su desarrollo en algunos campos, confinándolo a otros. Esto se debe a que el proceso primario: (a) carece de negativos, y (b) pone el énfasis en las relaciones y no en quién es quién en ellas ni en cuál es la dirección de la relación. Lo primero hace que el no que le dé el proceso secundario al desarrollo de pautas de proceso primario no fun- 
cione como negación en este último código, sino que, por el contrario, al poner el énfasis en lo que es negado, dé impulso a su desarrollo. Lo segundo significa que el proceso primario no puede establecer límites impermeables entre las relaciones que tienen lugar entre seres humanos y las que tienen lugar entre seres humanos y otros fenómenos naturales $-\mathrm{y}$, en consecuencia, que los intentos que el proceso secundario hace por imponer distintas pautas a los dos ámbitos de relaciones no pueden ser plenamente efectivos.

(2) Además, ignora que las relaciones instrumentales con el medio ambiente se encuentran en la raíz de la crisis ecológica que amenaza con destruirnos. Como hemos visto, a partir de un estado no-relacional que podríamos llamar "de comunión”, se desarrollan las relaciones comunicativas, las cuales, más adelante, son sustituidas por las relaciones instrumentales, que se extienden a todos los ámbitos y se hacen cada vez más pronunciadas sin que nada pueda detener su desarrollo. Los indígenas americanos, como los tibetanos prebudistas y los aborígenes de muchas regiones, se encontraban en el estadio comunicativo y por ende se relacionaban con los fenómenos naturales como si se tratase de personas y no de meras cosas carentes de vida: todas sus relaciones eran comunicativas. Y, como lo muestran las declaraciones proféticas de varios sabios indígenas (entre las cuales la más conocida - aunque en una adaptación realizada en el siglo XX por un guionista de cine- quizás sea la respuesta del jefe Seattle a la propuesta del Presidente de los EE. UU. de comprar las tierras de su tribu), habiendo entrado en contac- to con los invasores anglosajones y percibido la actitud de éstos hacia la Naturaleza, los indígenas norteamericanos predijeron claramente la crisis ecológica que amenaza con destruirnos.

Lo anterior explica el alto grado de conciencia ecológica de las culturas amerindias, que eran maestras en el arte de la conservación. En efecto, una de las pruebas más contundentes de la superioridad de la condición de los seres humanos originarios la encontramos en los hallazgos antropológicos y etnológicos divulgados en el artículo de Philippe Descola (1996) "Les cosmologies des indiens d'Amazonie. Comme pour leurs frères du nord, la nature est une construction sociale”. Según las investigaciones en cuestión, en el Amazonas, cuyas tierras son muy poco fértiles, las zonas que los indígenas han habitado por un mayor tiempo son las que exhiben una mayor biodiversidad. En cambio, en el caso de sociedades “civilizadas", las zonas que han estado habitadas por seres humanos por mayor tiempo son las que exhiben una menor biodiversidad, pues el medio ambiente ha estado sometido a la rapiña humana desmesurada y a lo que Gregory Bateson designó como "propósito consciente contra la naturaleza”. Tom Dale y Vernon Gill Carter (1955) mostraron que la mayoría de las grandes civilizaciones se autodestruyeron debido al mal uso que hicieron del medio ambiente, y en este momento la humanidad entera amenaza con autodestruirse por los mismos medios.

14 El "doble constreñimiento" (double bind) es una pauta comunicativa "descubierta” y bautizada por Gregory Bateson (1972) cuando, en 
engañándonos acerca del hecho de que nos estamos engañando - que es lo que Sartre llamó "mala fe".

Para afirmar esto, Habermas se ve forzado a declarar que si el receptor de los mensajes de los medios de difusión de masas acepta por su propia voluntad los juicios abiertos o encubiertos que contiene la información, ha habido acción comunicativa. Nosotros consideramos que, por el contrario, para que una acción sea comunicativa, quien al emprende tiene que tratar al destinatario de la acción como un sujeto a respetar y no como una cosa a manipular. En Capriles (1994) afirmé que lo que determina el verdadero carácter de un acto, o de un fenómeno producido por los seres humanos es, por una parte, el interés y la intención de quienes lo originan, $y$, por la otra, la estructura del fenómeno mismo. Si la intención de los creadores de los periódicos era manipular a las masas, y la estructura de los medios de difusión de masas en general es unidireccional, de modo que transmite mensajes manipulantes que los receptores no pueden contestar y que el medio que los transmite presenta como la verdad, difícilmente podremos decir que la acción que los produjo haya sido comunicativa. La comunicación es necesariamente bidireccional o multidireccional, y entre las partes ha de existir un mínimo de igualdad de autoridad. 